\title{
Evaluation of a sustained-release oral tetracycline in non-specific urethritis
}

\author{
PATRICIA M. PERERA \\ fames Pringle House, Middlesex Hospital, London
}

The treatment of non-specific urethritis (NSU) continues to challenge venereologists despite long experience with the disease. After two decades the tetracyclines remain the most effective therapeutic measure (King, 1973), in the form of 5, 10, or 21-day courses (Parker, 1972; Carroll, 1973; John, 1971). The present study was designed to investigate the efficacy of two currently available tetracycline preparations in the treatment of NSU, using a twice-daily treatment regime. Oxytetracycline, in a dosage of $500 \mathrm{mg}$. twice daily, is routinely used at this clinic in the treatment of NSU, as it is known that a twicedaily dosage greatly increases the likelihood that patients will take the complete course of medication.

\section{Material and method}

The group studied consisted of 259 men who attended the clinic with NSU between September and December, 1973; these patients were enrolled into the clinical trial, the only element of selection being that they had not been treated for NSU in the preceeding 3 months. The diagnosis of NSU was made, in each case, by the exclusion of gonorrhoea and trichomoniasis after examination of urethral discharge by a Gram-stained smear, a wet preparation, and a culture for both organisms.

The treatment consisted of a double-blind administration of either encapsulated oxytetracycline (ImperacinI.C.I.) or encapsulated tetracycline hydrochloride (Tetrabid-Organon), the latter preparation being a sustainedrelease formation designed specifically for twice-daily administration (Pines, Khaja, Greenfield, Raafat, Sreedharan, and Linsell, 1972). The two forms of medication, specially prepared for the trial, were physically indistinguishable and were dispensed in identical numbered containers, from a randomized list, to provide 5 days' treatment as follows:

TETRABID ORGANON Regular $250 \mathrm{mg}$. capsules were used throughout and to each patient was dispensed one envelope containing two loose capsules + one bottle of a further nine capsules.

IMPERACIN Using capsule cases identical with those of Tetrabid-Organon capsules were prepared containing either 250 or $500 \mathrm{mg}$. Imperacin. To each patient was dispensed one envelope, containing two loose $250 \mathrm{mg}$. capsules + one bottle of a further nine $500 \mathrm{mg}$. capsules.

Using this scheme, all patients were able to follow a regime of two capsules statim followed by one capsule every 12 hrs for a total of 5 days' treatment.

Instructions for taking the capsules were given by the physician when the medication was dispensed and was also written on the containers. Each patient was asked to avoid milk and milk products around the time of taking the capsules and was advised to refrain from sexual activity and the consumption of alcohol during treatment.

All data concerning the diagnosis, signs and symptoms, trial number, etc., were recorded on special forms.

At each subsequent follow-up examination the routine was similar to that at diagnosis. Patients were asked to hold their urine for at least $3 \mathrm{hrs}$ before attending for follow-up and urethral smears and cultures were taken at all examinations irrespective of the presence or absence of obvious discharge. A successful response to treatment was defined as absence of urethral discharge together with a clear urine at 7 days and again at 28 days after starting treatment. When a patient returned for follow-up examination with a recurrence of signs, with or without symptoms (recurrence being taken to mean either relapse or reinfection) he was re-treated with a further 5 days' course of the same tetracycline as he received initially. This was achieved without breaking the double-blind code. In such cases the patient was asked to return for follow-up examination 7 days later.

\section{Results and discussion}

In the Tetrabid-Organon treatment group the men ranged in age from 18 to 66 yrs (mean 26); 32 were married, and 98 were single, separated, divorced, or widowered. 59 had a past history of NSU. The incubation period was less than 10 days in 79,10 or more days in 35, and of doubtful or unknown duration in sixteen.

In the oxytetracycline treatment group the age range was 18 to $60 \mathrm{yrs}$ (mean 27); 35 were married and 94 were single, separated, divorced, or widowered. 48 had a past history of NSU. The incubation period was less than 10 days in 68,10 or more days in 44 , and of doubtful or unknown duration in seventeen.

Of the 259 men who were seen for diagnosis, 233 returned for at least one follow-up examination 
(Figure). Of the 26 patients who failed to return, thirteen had received oxytetracycline and thirteen had received Tetrabid-Organon medication. Since these patients defaulted in equal numbers irrespective of the medication received, it is felt reasonable to analyse, in greater detail, data from those patient in whom follow-up was possible as a basis for a comparison of the two forms of tetracycline therapy.

The Figure illustrates the extent to which patients receiving one of the two forms of tetracycline returned for follow-up examination and highlights the increase in default rate with time. Inevitably, some patients were seen at intervals other than 7 and 28 days after initial diagnosis but such cases are allowed for in the Figure.

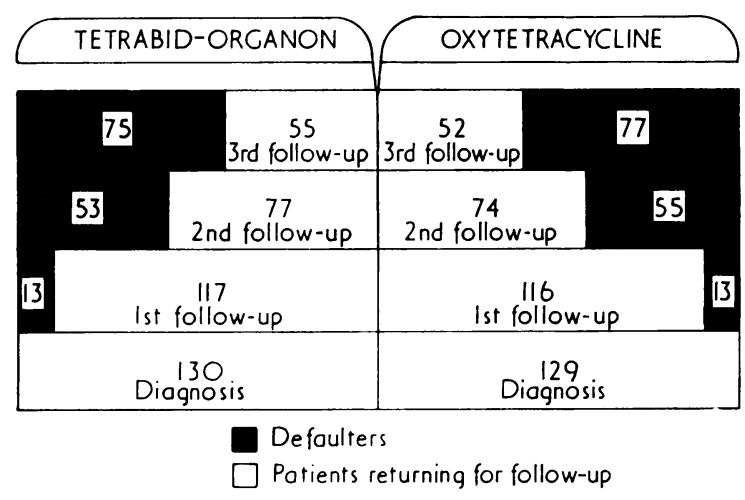

FIGURE Default rate related to medication. Data have been included from patients who returned at times other than those recommended

The percentages of patients successfully treated were very similar with the two preparations at the first follow-up examination within 10 days (Table I).

TABLE I Findings at 10 days after treatment

\begin{tabular}{|c|c|c|c|c|}
\hline \multirow[b]{2}{*}{ Medication } & \multicolumn{4}{|c|}{ No. of patients } \\
\hline & $\begin{array}{l}\text { Returning } \\
\text { within } \\
10 \text { days }\end{array}$ & $\begin{array}{l}\text { Failing to } \\
\text { return } \\
\text { within } \\
10 \text { days }\end{array}$ & $\begin{array}{l}\text { Free of } \\
\text { signs and } \\
\text { symptoms }\end{array}$ & $\begin{array}{l}\text { Requiring } \\
\text { re- } \\
\text { treatment }\end{array}$ \\
\hline Tetrabid-Organon & 97 & 33 & 89 & 8 \\
\hline Oxytetracycline & 98 & 31 & 90 & 8 \\
\hline Total & 195 & 64 & 179 & 16 \\
\hline
\end{tabular}

For the purpose of this comparison, all those patients returning within 10 days of initial diagnosis have been included; a number of patients were not able to return at precisely 7 days. Within the first 10 days, therefore, out of the initial sample of 259 patients, 195 (75 per cent.) returned for first follow-up examinations; but 64 patients ( 25 per cent.) failed to do so, including the 26 mentioned above who did not return at all. Among those who returned, 179 were free of all signs and symptoms; 90 had received oxytetracycline treatment and 89 had received Tetrabid-Organon.

Sixteen patients who returned required retreatment because of a recurrence of signs, with or without symptoms; eight of these patients had received oxytetracycline treatment and eight had received Tetrabid-Organon. When the sixteen retreated patients were followed-up further, thirteen returned free of signs and symptoms within the ensuing 10-day period after re-treatment and three failed to return to the clinic again.

Additionally, seven patients returned to the clinic with signs and symptoms between 10 and 14 days after treatment; all had been treated initially with oxytetracycline. They were re-treated with the same preparation. Five returned 7 days later free of signs and symptoms and two required a third course of treatment.

When the findings at 28 days after the initial diagnosis are analysed, (excluding 23 patients retreated within the first 14 days), it is found that 127 returned to the clinic (Table II); 28 patients for the first time and 96 for the second or third time. Of these patients 74 had been treated with TetrabidOrganon and one (1.3 per cent.) required further treatment; 53 had received oxytetracycline and twenty $(37 \cdot 7$ per cent.) required further treatment (Table II).

TABLE II Findings at 28 days after treatment

\begin{tabular}{|c|c|c|c|c|}
\hline \multirow[b]{2}{*}{ Medication } & \multicolumn{4}{|c|}{ No. of patients } \\
\hline & $\begin{array}{l}\text { Not re- } \\
\text { treated } \\
\text { returning } \\
\text { for follow- } \\
\text { up at } \\
28 \text { days }\end{array}$ & $\begin{array}{l}\text { Free of } \\
\text { signs and } \\
\text { symptoms }\end{array}$ & $\begin{array}{l}\text { Requiring } \\
\text { re- } \\
\text { treatment }\end{array}$ & $\begin{array}{l}\text { Clear at } \\
10 \text { days, } \\
\text { but not } \\
\text { returning } \\
\text { at } \\
28 \text { days }\end{array}$ \\
\hline Tetrabid-Organon & 74 & 73 & 1 & 34 \\
\hline Oxytetracycline & 53 & 33 & 20 & 49 \\
\hline Total & 127 & 106 & 21 & 83 \\
\hline
\end{tabular}

There were 83 patients who were found to be clear of signs and symptoms at the first follow-up examination but who did not return at 28 days, so that it is impossible to assess what the real cure-rate would have been. Clearly some patients failed to return because they had no further problems.

It is difficult to assess with accuracy the influence of re-infection due to sexual activity during the treatment period and the influence of consumption of alcohol during this time. There always remains the possibility of relapse. Nevertheless, all patients were asked, at return visits to the clinic, about sexual 
activity and alcohol consumption. An examination of the data collected in this way shows a close correlation between these two factors and recurrence.

Among patients who returned symptom and sign free, 3 per cent. of Tetrabid-Organon-treated patients admitted to sexual activity during treatment and 21 per cent. to the consumption of alcohol. In the oxytetracycline group these figures were 5 and 26 per cent. respectively. By comparison, among those who returned for re-treatment, 46 per cent. of Tetrabid-Organon-treated patients admitted to sexual activity and 72 per cent. to the consumption of alcohol, whereas in the oxytetracycline group these figures were 58 and 78 per cent. respectively. Wherever possible the patients' contacts were traced and treated on epidemiological grounds. Data concerning these contacts show that, amongst patients receiving oxytetracycline who required retreatment, 19 per cent. had contacts who were treated for non-specific infection, whereas in the retreated Tetrabid-Organon group 13 per cent. had contacts who were treated.

These figures suggest that sexual activity and alcohol may have had some influence on the re-treatment rate in the oxytetracycline-treated group, but the influence of the factors appears insufficient to account for the marked difference in the re-treatment rates observed in the two groups. Almost all patients with NSU continue to work and are unlikely to take drugs regularly during the day, so that a twice-daily dosage is usually taken more regularly by such patients than a regime requiring more frequent dosage.

The results of this trial suggest that TetrabidOrganon, a preparation designed specifically for twice-daily dosage is more effective than oxytetracycline given in the same manner.

Provision was made in the clinical trial to record patients' side-effects should they occur during the treatment period. Throughout the whole study the only complaints registered were two cases of slight nausea. In both cases the patients had received oxytetracycline.

\section{Summary}

A double-blind trial of oxytetracycline (ImperacinI.C.I.) and tetracycline hydrochloride in a sustainedrelease formulation (Tetrabid-Organon) was carried out on 259 men suffering from non-specific urethritis. Patients who had NSU in the preceeding 3 months were excluded from the trial. The response to treatment assessed at 10 days was favourable in ninety patients out of 129 (35 per cent.) who received oxytetracycline and in 89 patients out of 130 (34 per cent.) who received Tetrabid-Organon. Eight patients in each group required re-treatment and the remainder failed to attend for follow-up. At 4 weeks after treatment one (1.3 per cent.) of 74 patients treated with Tetrabid-Organon and twenty ( 37.7 per cent.) of patients treated with oxytetracycline required further treatment. A large proportion of patients who were free of signs and symptoms at the first follow-up failed to return at 4 weeks, so that the true rates of cure at 4 weeks are difficult to assess.

In a field such as venereology, the twice-daily administration of medication offers distinct advantages over a four-times-daily regime. This study suggests that Tetrabid-Organon, a tetracycline designed specifically for twice-daily dosage, is more effective than standard oxytetracycline, given twice daily, in the treatment of NSU.

It was satisfying to find that the traditional advice concerning abstention from sexual activity and alcohol consumption during the treatment of NSU has a sound basis. The study showed a close correlation between recurrence of NSU and failure to follow such advice. It would be interesting to investigate the means by which alcohol consumption may act to delay recovery.

The author is particularly indebted to Dr. R. D. Catterall, Director of James Pringle House, for his assistance and for allowing access to study patients from the James Pringle House clinic. Additionally, the author wishes to thank Mr. B. Pearce and nursing staff colleagues for their help and constant co-operation, and Mr. D. R. Thomas of Organon Laboratories Limited for help with the planning and with the supply of medication for the study.

\section{References}

Carroll, B. R. T. (1973) Brit. F. clin. Pract., 27, 211

JoHN, J. (1971) Brit. f. vener. Dis., 47, 266

KING, A. J. (1973) In 'Price's Textbook of the Practice of Medicine', ed. R. Bodley-Scott, 11th ed., p. 151. Oxford University Press.

PARKER, J. D. J. (1972) Med. Gynaec. Sociol., 6, no. 5, p. 9

Pines, A., Khaja, G., Greenfield, J. S. B., RaAfat, H., SREEDHARAN, K. S., and LiNDSELL, W. D. (1972) Brit. F. clin. Pract., 26, 475 